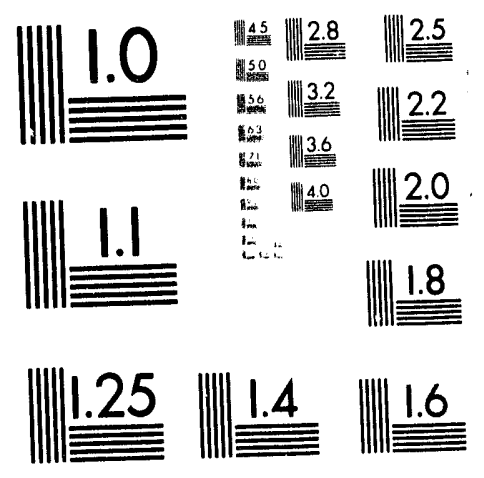



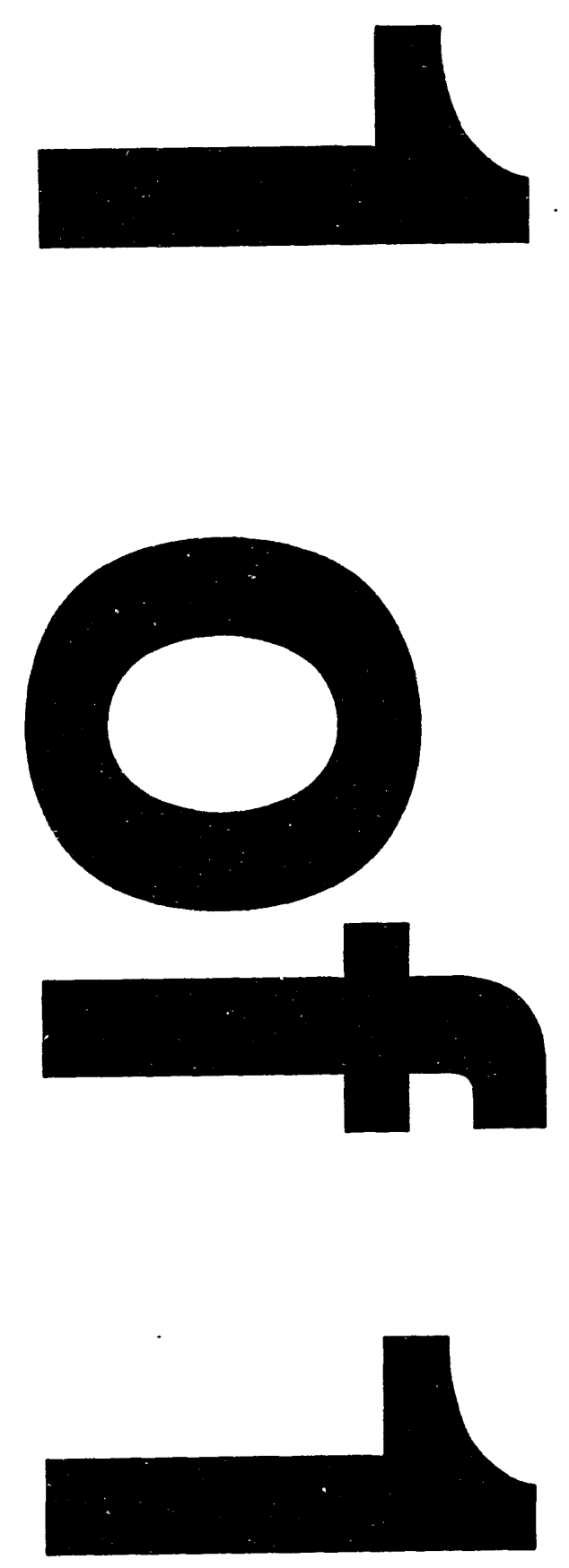


\section{RADIATION MONITOR REPORTING REQUIREMENTS}

by

W. F. Bates

Westinghouse Savannah River Company

Savannah River Site

Aiken, South Carolina 29808

DOE Contract No. DE-AC09-89SR18035

This paper was prepared in connection with work done under the above contract number with the U. S.

Department of Energy. By acceptance of this paper, the publisher and/or recipient acknowledges the U. S.

Government's right to retain a nonexclusive, royalty-free license in and to any copyright covering this paper, along with the right to reproduce and to authorize others to reproduce all or part of the copyrighted paper. 


\section{DISCLAIMER}

This report was prepared as an account of work sponsored by an agency of the United States Government. Neither the United States Government nor any agency thereof, nor any of their employees, makes any warranty, express or implied, or assumes any legal liability or responsibility for the accuracy, completeness, or usefulness of any information, apparatus, product, or process disclosed, or represents that its use would not infringe privately owned rights. Reference herein to any specific commercial product, process, or service by trade name, trademark, manufacturer, or otherwise does not necessarily constitute or imply its endorsement, recommendation, or favoring by the United States Government or any agency thereof. The views and opinions of authors expressed herein do not necessarily state or reflect those of the United States Government or any agency thereof.

This report has been reproduced directly from the best available copy.

Available to DOE and DOE contractors from the Office of Scientific and Technical Information, P. O. Box 62, Oak Ridge, TN 37831; prices available from (615) $576-8401$.

Available to the public from the National Technical Information Service, U. S. Department of Commerce, 5285 Port Royal Rd., Springfield, VA 22161 
G. T. Wright, 703-H

J. W. French, 703-H

T. M. Monahon, 703-H

V. G. Dickert, 703-H

R. W. Wilson, 707-H

E. R. Losure, 707-H

G. Davis, 703-F

M. S. Peters, 241-100F

G. D. Thaxton, 241-119H

R. L. Salizzoni, 707-H

W. C. Clark, 703-H

W. F. Bates, 703-H

M. A. Ceravolo, 707-H

B. R. Hess, 241-102F

A. W. Wiggins, $241-84 \mathrm{H}$

K. F. Lesko, 707-H

T. D. Phillips, 703-H

E. M. Tshishiku, 703-H

M. D. Johnson, 703-H

C. A. Polson, 241-84H

E. R. Ennis, 241-120H

C. A. Roach, 703-H

E. A. Cabacungan, 703-H

T. B. Caldwell, 703-H

P. D. d'Entremont, 703-H

R. R. Abshire, 703-H

Technical Information Mgt., 703-43A (4 copies) 
HIGH LEVEL WASTE ENGINEERING

FACILITY ENGINEERING SECTION

WSRC-TR-93-634

REVISION: 0

KEYWORDS:

Occurrence

Off-Normal

Class B

RETENTION:

PERMANENT

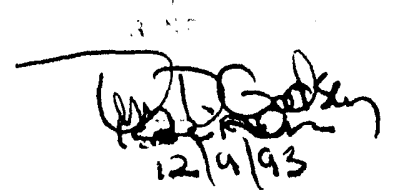

CLASSIFICATION:

$\frac{\lim (x)}{\text { Authorized Derivative }}$

\section{RADIATION MONITOR REPORTING REQUIREMENTS (U)}

\section{BY}

W. F. BATES

ISSUED: $12 / 10 / 93$

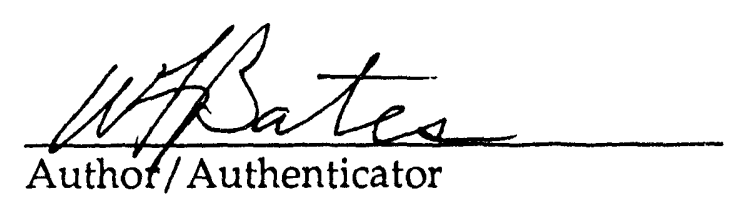

Date: $12 / 10 / 93$

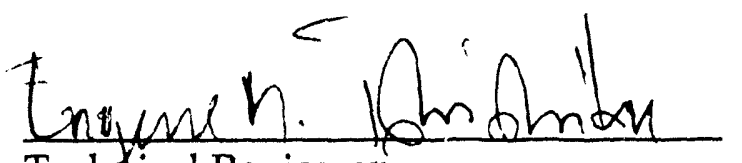

Technical Reviewer
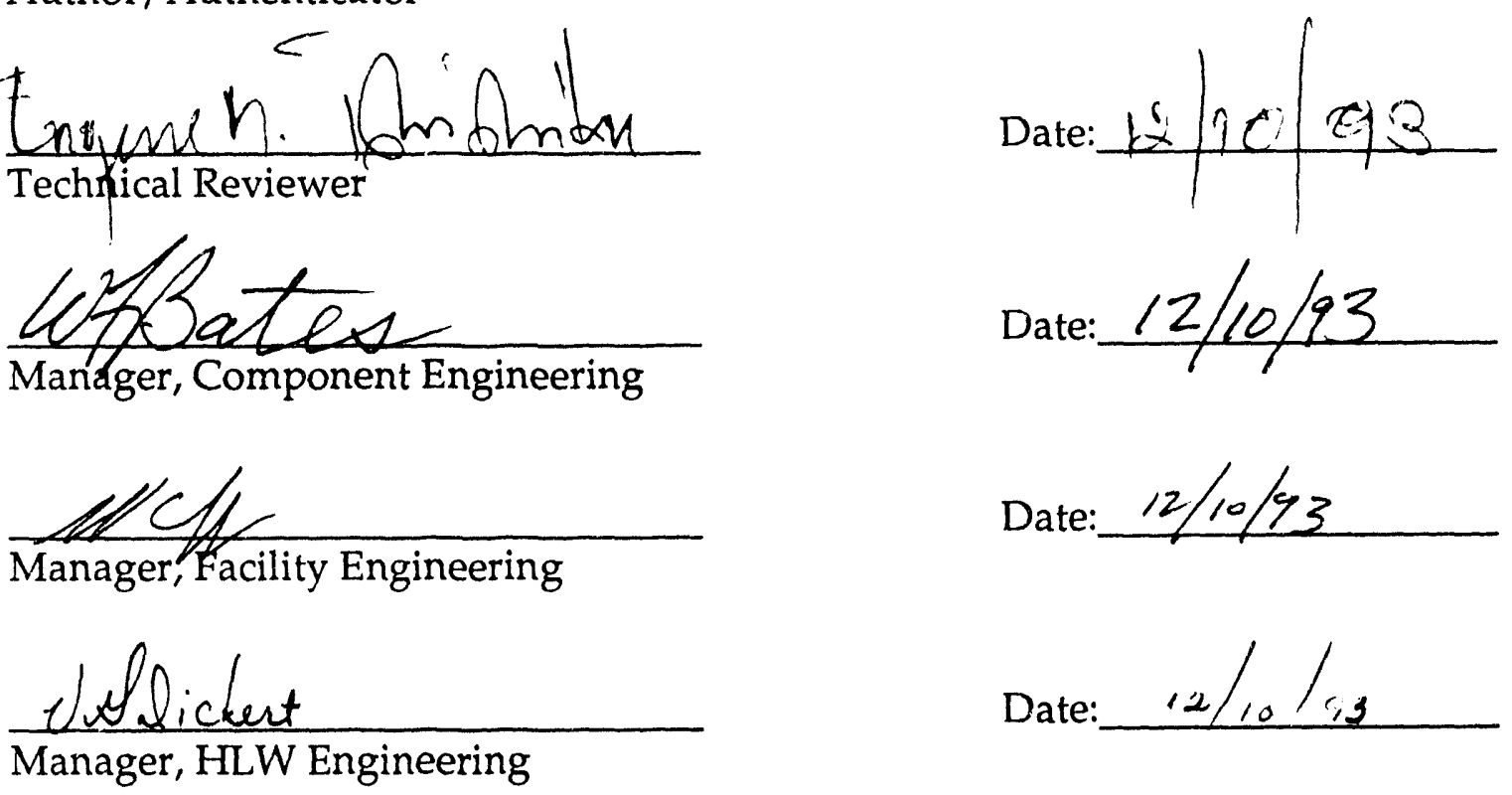
WSRC-TR-93-634

Page 2 of 12

December 10, 1993

\section{INTRODUCTION}

Within High Level Waste Management (HLWM), CAMs and VAMPs are currently considered Class B equipment, therefore, alarm conditions associated with the CAMs and VAMPs result in an Unusual Occurrence or Off-Normal notification and subsequent occurrence reporting. Recent equipment difficulties associated with Continuous Air Monitors (CAMs) and Victoreen Area Radiation Monitors (VAMPs) have resulted in a significant number of notification reports. These notifications have the potential to decrease operator sensitivity to the significance of specific CAM and VAMP failures. Additionally, the reports are extremely costly and are not appropriate as a means for tracking and trending equipment performance. This report provides a technical basis for a change in Waste Management occurrence reporting categorization for specific CAM and VAMP failure modes.

\section{SUMMARY}

Most equipment difficulties associated with CAMs and VAMPs are annunciated and conservative actions are taken per existing alarm response procedures. After review of the DOE orders and the performance requirements of the CAMs and VAMPs, recommendations were developed and documented in this report to change the categorization and occurrence reporting criteria for both systems. Only in cases where personnel protection is significantly affected or where regulatory environmental monitoring is involved should CAM and VAMP alarms be reported as Unusual Occurrences or Off-Normal events. In summary, the function of the evaporator, waste tank purge, waste tank annulus, and all miscellaneous HLWM CAMs is process monitoring, not protection of facility or co-located facility workers. Based on the conservative design and procedural alarm responses for VAMP radiation and failure alarm conditions, most VAMP equipment difficulties which are annunciated are not considered to be a degradation of protection for facility or co-located facility workers. The recommendations include changes to the Waste Management occurrence categorization, notification and reporting procedure. The detailed justification for these recommendations is provided in the Discussion.

\section{DISCUSSION}

The requirements for notifications and event classifications for reporting are included in Department of Energy Order 5000.3B (Ref. 1, See applicable sections in Attachment 1). This order specifically provides criteria for reportable Unusual Occurrences and Off-Normal Occurrences. High Level Waste Management (HLWM) implements these definitions and categorizations in WM-IM-5411, WM 
WSRC-TR-93-63.4

Page 3 of 12

December 10,1993

Occurrence Identification, Categorization, Notification, and Initial Reporting (U) (Ref. 2). This procedure defines the classifications as follows:

Unusual Occurrence (UO) - A non-emergency occurrence that has significance impact or potential on safety, environment, health, security or operations.

Off-Normal Occurrence (ON) - Abnormal or unplanned Events, Conditions, or Concerns that adversely affect, potentially affect, or are indicative of degradation in the safety, environmental, or health protection performance or operation of a facility.

Non-Routine Occurrence (NR) - An Event, Condition or Concern that should not happen during normal operation or maintenance; or is outside the scope of normal procedures and may warrant an evaluation for corrective actions. A Non-Routine Occurrence does not necessarily immediately impact safety, health, quality assurance, security, operations, maintenance, or have immediate environmental implications.

The following discussion is divided to discuss CAM and VAMP component function, normal procedure responses to specific associated alarms, and recommended categorization and notification requirements. It is understood that numerous equipment difficulties have been encountered on CAMs and VAMPs recently. Action plans have been developed to address hardware and procedural issues to improve reliability of the associated CAM and VAMP equipment (Ref. 3,4).

\section{Continuous Air Monitors (CAMs)}

In July 1993, a team was formed to investigate the existing codes and standards which apply to the HLWM facility CAMs and air samplers. The results of the study were documented in a position paper, J-ESR-G-00001, Position Paper, Project S-4516, Waste Tanks, Codes, Orders, and Standards, Constant Air Monitors (U) (Ref. 5). The position paper provides interpretation of applicable DOE Orders and other codes and standards related to airborne effluent monitoring of waste tanks. Section 4.0 of Reference 5 states that based on the Federal Facilities Compliance Agreement (FFCA), the continuous sampling and effluent activity alarms of the F \& $\mathrm{H}$ Area waste tank purge and annulus exhausts must be continued. The intent was to maintain the current sampling practices. The agreement does not require the installation of continuous measurement devices (in-line or off-line radionuclide detectors) on the purge or annulus exhausts where only sampling exists now. Reference 5 section 6.1 concludes that a representative sample of the radioactive particulate from the type III and IIIA F and H Area waste tank purge and annulus exhausts shall be 
WSRC-TR-93-634

Page 4 of 12

December 10, 1993

obtained using suitable filter media. Based on the source categories defined in Reference 6, the same is true for all Waste Management exhaust systems including waste tank purge and annulus, evaporators, the $299-\mathrm{H}$ facility, and the Concentrate Transfer System (CTS). Only periodic confirmatory measurements of the exhaust flow rates are required (Ref. 5). The only exceptions to this are Tank 48 and Tank 49 purge and annulus CAMs. These CAMs will be required per the new Operaticnal Safety Requirements (OSRs) for the In-Tank Precipitation (ITP) Facility (Ref. 7).

CAMs consist of two functional parts. First, the CAM detector and associated electronics are provided for process monitoring. The second functional part of the CAMs is the air sampler which consists of the sample blower, box, piping, valves and rotometer, and filter paper. The CAMs are installed for different reasons in different applications. This report addresses HLWM waste tank purge and annulus exhaust CAMs, CAMs associated with waste evaporators and CTS, and all other miscellaneou: CAMs in HLWM facilities. Some CAMs are installed on the effluent side of the High Efficiency Particulate Air (HEPA) filter(s). These CAMs provide monitoring of HEPA filter performance by providing an alarm if high effluent air activity is detected. CAMs installed on exhaust ventilation systems which do not contain HEPA filters (specifically tank annulus) monitor activity in order to detect possible leakage from the waste tank into the annulus. In all the waste tank CAMs described here, the filter paper is periodically sampled to determine effluent releases and provide additional process monitoring. The HLWM CAMs are not provided for protection of facility or colocated facility workers. Personnel protection is maintained with process equipment such as HEPA filters and primary containment equipment.

Filter papers from all the air samplers (including those samplers which also have associated CAMs) are analyzed procedurally each week to meet the numerous environmental permit, DOE Order and other codes and standards requiring effluent air sampling of waste facility airborne exhaust. The surveillance is performed weekly per 5Q1.5, Procedure 314, 241-F \& 241-H Exhaust Monitoring Systems (Ref. 8). Site boundary source releases are determined based on the weekly composite measurements of the sampler filter papers.

Based on Reference 5, only periodic sampling is required for all exhaust systems described above except Tanks 48 and 49. Since CAMs are used as HEPA performance monitors and annulus in-leakage process indicators, these CAM alarms and equipment difficulties related to this function do not constitute an Off-Normal event per Reference 1. The performance requirement for CAMs is to alarm and notify HLWO of potential process upset conditions (HEPA filter breakthrough and annulus in-leakage) or to provide failure alarms in the event of a potential exhaust air sampling degradation. Since alarms are provided for both high activity and failure of the monitor and blower, and alarm responses are 
WSRC-TR-93-534

Page 5 of 12

December 10, 1993

taken procedurally, the overall intent to provide periodic air sampling is not threatened by most alarm conditions. Similarly, when a CAM fails to calibrate or does not respond properly to a source check, the required periodic air sampling is not threatened. Short time periods are permitted when air sample flow is isolated for leakage testing and source testing. Similarly, during the time from receipt of an alarm to the time $\mathrm{HP}$ investigates an alarm condition, continuous sampling is not required.

In the event that a high activity alarm or a CAM failure alarm is annunciated, formal response by High Level Waste Operations (HLWO) personnel is initiated per category 1 procedures 241F-369 and 241-H-369, CAM Alarm Responses (U) (Ref. $9 \& 10$ ). These response procedures require stopping work and exiting the affected area and require Health Physics (HP) personnel to survey and verify safe conditions when a high activity alarm is received. Similarly if the alarm is a failure alarm, exhaust fan shutdown is required if corrective maintenance will take a significant amount of time (greater than four hours). The associated HP response procedure invoked during response to alarms is $5 \mathrm{Q} 1.2$ procedure $130 \mathrm{U}$, Constant Air Monitor - Particulate Airborne Activity Alarm Response (Ref. 11).

Based on Reference 12, an occurrence report database search, and morning reports since the last database entry, approximately 49 CAM "Off-Normal" difficulties have been reported since early 1991. 44 of these occurred in the last year, indicating a heightened awareness of reporting criteria. Of these 44,30 resulted in annunciation of an alarm with appropriate alarm response activities or were surveillance failures. None of the 30 resulted in potential danger to environment, safety or health or prevented successful periodic air sampling. The remaining 14 would require further review to determine whether periodic representative sampling capability was degraded. Since excessive notifications and occurrence reports have the potential to lower the operator and management sensitivity to significant air sampling difficulties, the event classification should be specifically applicable to significant failures or potential conditions based on design basis documents (Safety Analysis Report, Operational Safety Requirements, Process Hazards Reviews, etc.), permits, and DOE Orders. The recommended reduction in reporting requirements is consistent with this practice.

In conclusion, the Waste Management CAMs are not considered personnel protection equipment. Therefore, it is recommended that the CAM alarms and equipment difficulties in the field not be reported as Unusual Occurrence, OffNormal, or Non-Routine unless:

- the CAM is associated with Tank 48 or 49 purge or exhaust 
WSRC-TR-93-634

Page 6 of 12

December 10, 1993

- the equipment difficulty prevented valid representative periodic sampling or flow or compliarce with regulatory monitoring requirements

- the alarm condition is determined to represent actual high activity conditions. This case is not a CAM problem, but a likely HEPA or tank leakage event.

To ensure equipment difficulties for CAMs are appropriately tracked and trended, the Works Management System may be utilized. Adminisirative controls and status boards are considered a more effective form of notification to HLWO personnel and are in alignment with current Conduct of Operations practices.

\section{Victoreen Area Radiation Monitors (VAMPs)}

The VAMPs are similar to the CAMs because they are all provided with control room annunciators which alarm when radiation exceeds alarm setpoints and when the VAMP detects internal difficulties (Ref. 13, 14). Both conditions result in the same alarm and the same procedural response per existing alarm response procedures (example: Ref. 15). Generally, these alarm response procedures direct HLWO personnel to generic response procedures for VAMPs which require HP notification, stoppage of work in the affected area, and exit of the affected area (Ref. 16). HP uses Reference 17 to respond to the alarm notification and treat all alarm conditions as real high radiation conditions until proven otherwise via results of a local area radiation survey. Because the same actions are taken in the rase of high radiation and failure alarm cases, the function of personnel protection is not degraded in either alarm condition. Only cases in which a radiation monitor is unable to alarm in a high radiation condition, is the function of personnel protection degraded.

The current reporting of VAMP equipment difficulties is frequent and may potentially lower the sensitivity of HLWO operators and management to significant VAMP difficulties. By decreasing the reporting requirements for these conditions, only the significant conditions which meet the above criteria will be reported.

Based on an Occurrence Summary Report database search, 19 Off-Normal occurrences were reported in 1993 associated with VAMPs in F and H-Tank Facilities, the Effluent Treatment Facility, the In-Tank Precipitation Facility and the $299-\mathrm{H}$ facility. Of the 19 Off-Normal reported occurrences, 13 occurrence reports could have been avoided if the recommended reporting and classification criteria were applied. 
The same reporting criteria from Reference 1 apply for reporting VAMP and CAM related occurrences. It is the intent to reduce the number of routine corrective maintenance activities reported per Reference 2. High Level Waste Engineering considers the definition of performance for a VAMP to be as follows:

The ability to alarm under high radiation conditions in the area or the ability to alarm when equipment difficulties are internally detected which may prevent accurate ability to alarm under high radiation conditions.

Personnel protection is only degraded if the performance described above cannot be maintained

The radiation alarm levels are controlled under Reference 18. If an alarm is received, alarm response procedures require HLWO and HP to take action as if the radiation is genuinely high until proven otherwise. Because of these administrative controls, it is not considered necessary to report equipment difficulties associated with individual VAMPs as Unusual Occurrences, OffNormal, or Non-Routine events unless:

- the equipment difficulty encountered may have resulted in masking of legitimate high activity alarm conditions (including out-of-calibration conditions)

- minimum required number of VAMPs in the vicinity are not operable as required by Operational Safety Requirements

- the alarm condition is an actual high radiation rate condition (this is not a VAMP difficulty, but a process and personnel concern).

Tracking and trending of equipment difficulties which do not meet the criteria above may be performed by searching the Works Management System.

\section{ACTIONS}

Have the Issue Administrator develop and implement the following changes to Reference 2 (MTS \#-93457 addresses recommendations 1 through 9, MTS\#-93458 addresses recommendation 10$)$ :

1. Remove "CAMs" from Attachment 1A section 3.B., first reportability criteria (exception of Tanks 48 and 49). (UO) 
WSRC-TR-93-634

Page 8 of 12

December 10, 1993

2. Change the second reportability criteria under Attachment 1A section 3.B. so that CAM alarms are not included (exception of Tanks 48 and 49). $(\mathrm{ON})$

3. Change the second reportability criteria under Attachment 1A section 3.B. so that VAMP alarms are not included unless the ability of the VAMP to provide actual high radiation alarm AND failure alarm is degraded. (ON)

4. Change the fourth reportability criteria under Attachment 1A section 3.H. so that precautionary exit from affected areas caused procedurally by CAM and VAMP alarms is not included in the criteria. (ON)

5. Change the first reportability criteria under Attachment 1A section 6.B. so that precautionary exit from affected areas caused procedurally by CAM and VAMP alarms is not included in the criteria. (ON)

6. Change the third reportability criteria under Attachment 1A section 12.B. so that an exception is provided for CAMs provided that air sampling capability is not degraded (exception of Tanks 48 and 49). (ON)

7. Change the third reportability criteria under Attachment 1A section 13.A. so that an exception is provided for VAMPs provided that ability to alarm on high radiation conditions or the ability to alarm when the unit diagnostic circuitry detects possible inability to alarm on high radiation remains intact. This may be accomplished with a note on Attachment 1B. $(\mathrm{ON})$

8. Change the third reportability criteria under Attachment 1A section 13.A. so that an exception is provided for CAMs provided that air sampling capability is not degraded. This may be accomplished with a note on Attachment 1B (exception of Tanks 48 and 49). (ON)

9. Downgrade past events which are currently in the reporting cycle.

10. Consider change in functional design classification for CAM and VAMP hardware based on this report.

\section{CONTRIBUTORS}
E. M. Tshishiku
W. C. Clark
P. D. d'Entremont
T. B. Caldwell
C. A. Roach
R. R. Abshire
W. B. Renfro 


\section{REFERENCES}

1. DOE Order 5000.3B, Attachment I, Categorization of Reportable Occurrences, Chg. 1, July 2, 1993.

2. Manual SW6, WM-IM-5411, WM Occurrence Identification, Categorization, Notification, and Initial Reporting (U), Revision 8, August $17,1993$.

3. Roach, C. A., HLW-HLE-931446, Reliability and Operational Evaluation of H and F Tank Farm VAMPs (U), October 26, 1993.

4. Cabacungan, E. A., HLW-HLE-93-1492, Continuous Air Monitors (CAMs) Action Plan (U), DRAFT, November 22, 1993.

5. J-ESR-G-00001, Position Paper, Project S-4516, Waste Tanks, Codes, Orders, and Standards, Constant Air Monitors (U), Revision 0, July 30, 1993.

6. Manual WSRC-3Q1-2 Volume 1, Environmental Monitoring Section Plan and Procedures, (Attachment 3-1, WSRC-IM-91-60, National Emissions Standards for Hazardous Air Pollutants Quality Assurance Plan (U)), Revision 3, April 6, 1993.

7. WSRC-RP-90-1124, Operational Safety Requirements, In-Tank Precipitation, LCO 3.3.3, Revision 3, August 1, 1993.

8. Health Physics Department Air Effluent Monitoring Procedure 5Q1.5, Procedure 314, 241-F \& 241-H Exhaust Monitoring Systems, Revision 4, September 24, 1993.

9. Manual SW9, Procedure 241-F-369, CAM Alarm Responses (U), Revision 1, October 1, 1993.

10. Manual SW9, Procedure 241-H-369, CAM Alarm Responses (U), Revision 1, October 1, 1993.

11. HP Manual 5Q1.2 Procedure 130U, Constant Air Monitor - Particulate Airborne Activity Alarm Response, Revision 1, May 15, 1992.

12. WER-HLE-93-1258, Performance Indicators - September 1993, Memorandum from R. A. Scaggs to G. T. Wright, November 4, 1993. 
WSRC-TR-93-634

Page 10 of 12

December 10, 1993

13. Memorandum from B. J. Arnold to R. R. Abshire, Ref: Issue Number 90-47, April 8, 1991.

14. Memorandum from V. G. Dickert to R. R. Abshire, Subj: Occurrence Report SRS-FTANK-90-47, July 19, 1991.

15. Manual SW27, Alarm Response Procedure (ARP) 241-82H-ARP-7400B-71A, TK48 VAMP High Activity, Revision 0, April 3, 1991.

16. Manual SW9, Procedure 241-FH-3, Area Radiation Monitor Alarm Response (U), Revision 21, August 3, 1993.

17. HP Manual 5Q1.2, Procedure 131U, Area Radiation Monitor Alarm Response Revision 0, June 10, 1991.

18. HP Manual 5Q1.7, Procedure 103, VAMP Area Radiation Monitor Annual Source Calibration, Revision 2.

19. WSRC-RP-93-224, Operational Safety Requirements, Extended Sludge Processing, Revision 1, August 1, 1993. 
WSRC-TR-93-634

Page 11 of 12

December 10, 1993

\section{ATTACHMENT 1 CATEGORIZATION OF REPORTABLE OCCURRENCES}

DOE ORDER 500.3B (sections applicable to CAMs/VAMPs)

Categorizations of Occurrences By Group (Group 1. Facility Condition)

E. A deficiency such that a structure, system, or component vital to safety or program performance does not conform to stated criteria and cannot perform its intended function.

\section{Unusual Occurrence}

(b) Events or conditions indicative of failure or performance degradation of systems designed, installed, and operated for the protection of facility or co-located facility workers (e.g.: fire protection systems, excluding those in office spaces; radiation monitoring systems such as continuous air monitors; criticality alarm systems; shielding; etc.), which prevent satisfactory performance of their design function (e.g., to alarm, control spread of contamination, etc.) when it is required.

\section{Off-Normal}

(b) Events or conditions indicative of performance degradation of systems designed, installed and operated for the protection of facility or co-located facility workers (e.g.; fire protection systems, excluding those in office spaces; radiation monitoring systems such as continuous air monitors; criticality alarm systems; shielding; etc.), which do not prevent satisfactory performance of their design function (e.g., to alarm, control spread of contamination, etc.) or which occurs when the system is not required (e.g., discovered during testing or inspection).

(c) Failure or significant performance degradation of any Class B Equipment.

(d) Discovery of defective item or service involving Class B equipment.

F. Violation of procedures (include maintenance requirements and system lineups) or inadequate procedures either of which result in adverse effects on performance, safety, or reliability.

\section{Off-Normal}

(c) Incorrect maintenance (including calibration) on or unauthorized modifications to Class B equipment. 


\section{Attachment 1 (cont.)}

G. Unsatisfactory Surveillance/Inspections

\section{Off-Normal}

(a) Any surveillance/inspection reporting unsatisfactory operation, testing, maintenance, or modification of any Class B Equipment.

(b) Any surveillance/inspection reporting improper procedural compliance with or lack of operator understanding regarding Class B Equipment.

I. Operations. Special attention should be paid to augmenting this section during the development of facility-specific procedures as required of Paragraph $8 \mathrm{~d}$ of the Order.

\section{Unusual Occurrence}

(a) Any actuation of safety systems, automatic protection systems, emergency systems or engineered safety features, except under approved testing.

\section{Off-Normal}

(f) Any facility evacuation (excluding office space) conducted as a precautionary measure, e.g. Fi.e, CAA, NM, or CAM alarms.

(g) Any actuation of systems designed, installed, and operated for protection of facility or co-located facility workers (e.g., fire protection systems, excluding those in office spaces; radiation monitoring systems such as continuous air monitors; criticality alarm systems; etc.) except under approved testing. Actuation of continuous air monitoring systems do not have to be reported if (a) their actuation was found to be due to radon-thoron effects on the system or (b) their actuation is expected due to maintenance tasks and other planned operations in the facility where the potential for release of radioactivity is anticipated to occur and the workers are appropriately protected. 

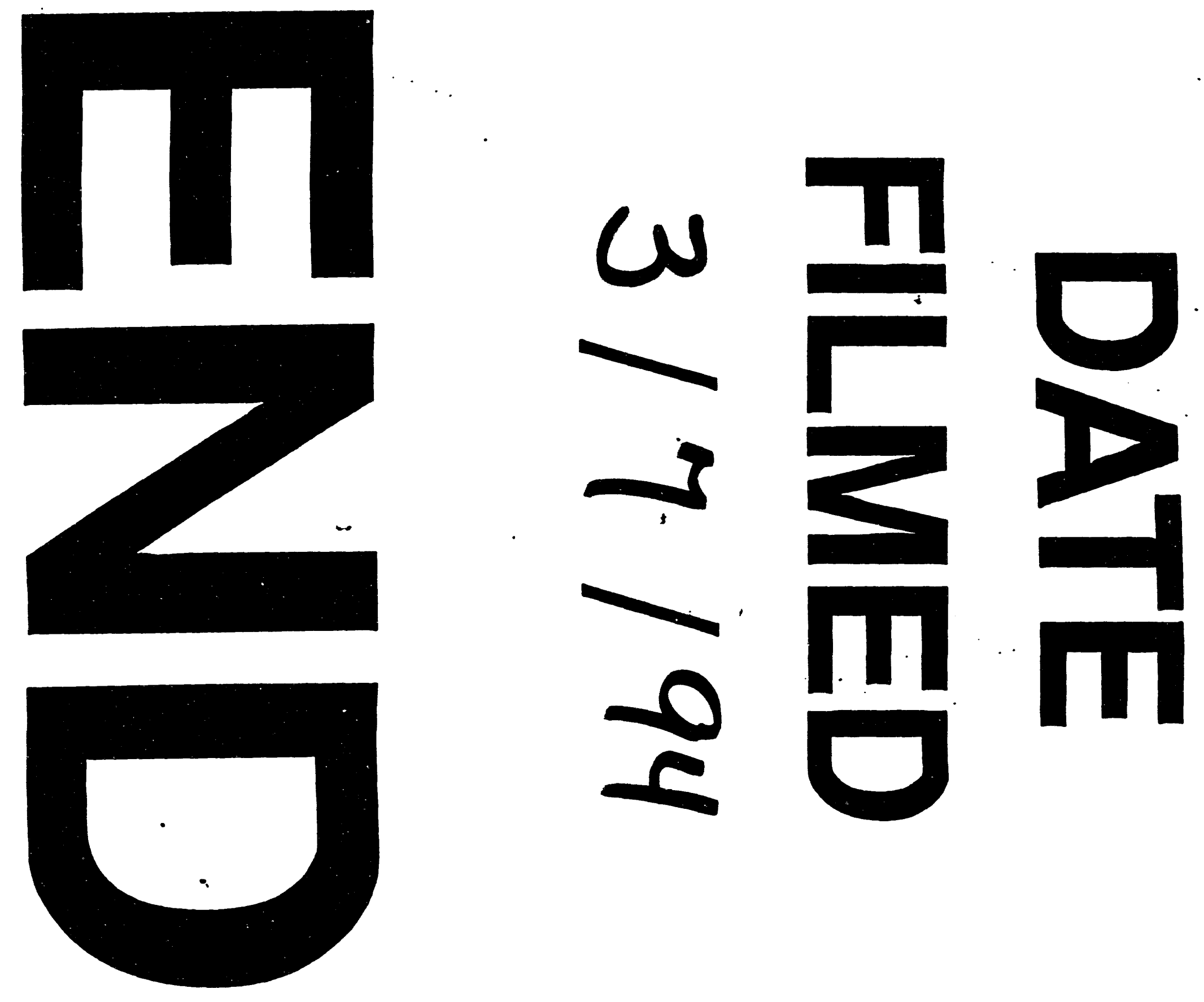
